International Journal of Engineering \& Technology, $7(2.7)(2018) 484-488$
International Journal of Engineering \& Technology
WPC
Website www.sciencepubco.com/index.php/IJET
Research Paper

\title{
Design of UWB Antenna with WLAN \& X-Band Notch for Wireless Communication
}

\author{
${ }^{1}$ K.V.Prashanth, ${ }^{2}$ A.Tejasri, ${ }^{3}$ K.Sandeep, ${ }^{4}$ U.Sateesh Kumar, ${ }^{5}$ G.Swarupa \\ 1,2,3,4,5 Department of Electronics \& Communication Engineering, \\ Koneru Lakshmaiah Education Foundation, Vaddeswaram, Guntur, AndhraPradesh, INDIA-522502. \\ *Email: prashanth32633@gmail.com
}

\begin{abstract}
In this proposition, a traditional UWB antenna with twofold indent channels was intended for a few remote applications. The exhibited antenna is outlined having estimations of $30 \times 35 \times 1.6 \mathrm{~mm} 3$ with a fix of rectangular staircase design. The dismissal bands are WLAN at $5 \mathrm{GHz}(5.1-5.8 \mathrm{GHz})$ and the satellite X-band from space to earth $(7.25-7.75 \mathrm{GHz})$. The patch with a step design with a modified $\pi$ formed opening gets the ultra-wide band. The UWB scope of $3.1-10.6 \mathrm{GHz}$ affirmed by FCC can possibly cause interferences in the various wireless systems applications.. With a specific end goal to lessen these interferences, we settled on the band indent. In this proposed outline, the WLAN has scores setting a U-molded opening in the patch and the X-band has indents with a reversed T-shape in the ground plane.
\end{abstract}

Keywords: Dual Band Notch, Staircase Rectangular patch, Ultra-Wideband, WLAN Band, X-Band.

\section{Introduction}

Ultra-wideband (UWB) antenna draw in awesome consideration in the remote world because of their preferences, which incorporate to a great degree low ghostly power thickness, fast information rate, high-precision extend, minimal effort and low multifaceted nature. Since the Federal Communications Commission (FCC) permitted 3.1-10.6 GHz recurrence go band for UWB correspondence [1]. UWB technology has been used in a wide range of applications such as radars, navigation, telemetry, biomedical systems, Global positioning systems (GPS), Mobile satellite communications, remote sensing and direct broadcast system (DBS) [2].

The design of UWB antenna has numerous issues. Interference is a tough problem for UWB application gadgets [3]. UWB $(3.1 \mathrm{GHz}$ to $10.6 \mathrm{GHz}$ ) includes other sub narrowband applications like WiMAX $(3.3-3.6 \mathrm{GHz})$ band, C-band operating in $(3.8 \mathrm{GHz}$ to 4.2 $\mathrm{GHz})$, WLAN band system at $5 \mathrm{GHz}(5.1-5.8 \mathrm{GHz})$ and X-band operating in (7.25-8.39 GHz band). One way for suppressing interference is to use spatial filters such as frequency selective surfaces (FSS) above the antenna [4].But it requires more space which is not a good aspect for antenna designing. The most of the antennas are designed with frequency band rejected function by the approach of embedding slots[5].Some of the frequently seen slots are square-slot [6],U-slot [7] , attaching bar [8],pi-slot [9], the Ushaped bar [5], V - fashioned opening [10], C - fashioned opening [11], $\mathrm{S}$ - fashioned opening in feed line[12] and so on many other approaches. The solid used for the substrate should be having dielectric value in the range of $2.2 \leq \varepsilon_{\mathrm{r}} \leq 12$. The solid used here is FR4 epoxy with dielectric value 4.4 and Dielectric loss tangent 0.02 . This design considered with 5 step staircase followed by rectangular patch \& inverted $\pi$-shaped slot with requisite slots along with feed line to attain UWB range practically[13-28]. The proposed antenna is notched with two bands, WLAN and X-band satellite communication and a complete parametric analysis is done using HFSS tool. Results include parameters like VSWR, gain and radiation pattern along with return loss characteristics ( $S$ parameter). Section II discusses about Parametric Design of the basic antenna. Then Section III discusses about two notches for WLAN \& X-Band of proposed antenna. Section IV relates to results \& conclusion of the designed final antenna

\section{Parametric Design of Basic UWB Antenna}

Figure-1 (a) \& (b) describes geometry of basic UWB Antenna which works under UWB range, practically gained $(2.9 \mathrm{GHz}$ $12.6 \mathrm{GHz}$ ). For substrate we have considered FR4 epoxy because of its cost effectiveness and has a decent dielectric value of 4.4 and dielectric loss tangent 0.02 , with a substrate size of $35 \times 30$ $\mathrm{mm}^{2}$ and height of $1.6 \mathrm{~mm}$. For patch we have considered 5 steps of stair case design and rectangular strips united with an inverted $\pi$-shaped slot at middle of rectangular sheet to attain UWB range. 


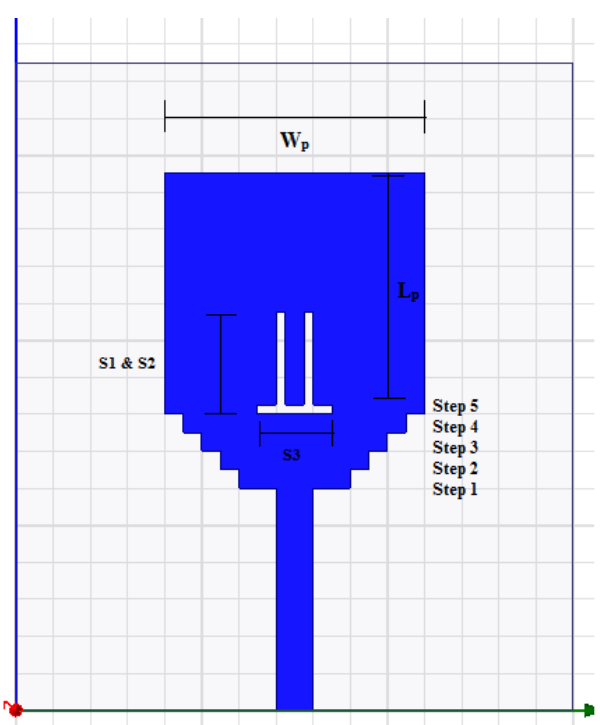

Figure 1(a): UWB basic antenna (top view)

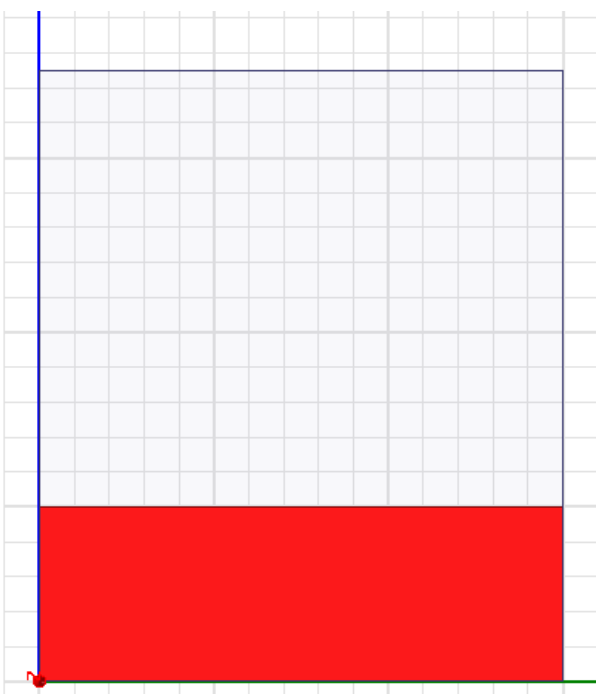

Figure 1(b): UWB basic antenna (bottom view)

The following table gives parametric dimensions of proposed antenna without any notching.

Table 1: Parametric values of basic UWB antenna

\begin{tabular}{|c|c|c|}
\hline S.No. & Parameter & Value in mm \\
\hline 1 & Length of conducting Patch & 12 \\
\hline 2 & Width of conducting Patch & 14 \\
\hline 3 & Length of FR4 Substrate & 35 \\
\hline 4 & Width of FR4 Substrate & 30 \\
\hline 5 & Length of line feed & 12 \\
\hline 6 & Width of line feed & 2 \\
\hline 7 & Length of Ground plane & 10 \\
\hline 8 & Width of Ground plane & 30 \\
\hline 9 & S1 ( $\pi$-shaped slot $)$ & $(0.5,5)$ \\
\hline 10 & S2 ( $\pi$-shaped slot $)$ & $(0.5,5)$ \\
\hline 11 & S3 ( $\pi$-shaped slot) & $(4,0.5)$ \\
\hline 12 & $\begin{array}{l}\text { Step1, } \\
\text { Step2, } \\
\text { Step3, } \\
\text { Step4, } \\
\text { Step5 }\end{array}$ & $\begin{array}{l}(6,1), \\
(8,1), \\
(10,1), \\
(12,1), \\
(14,1)\end{array}$ \\
\hline
\end{tabular}

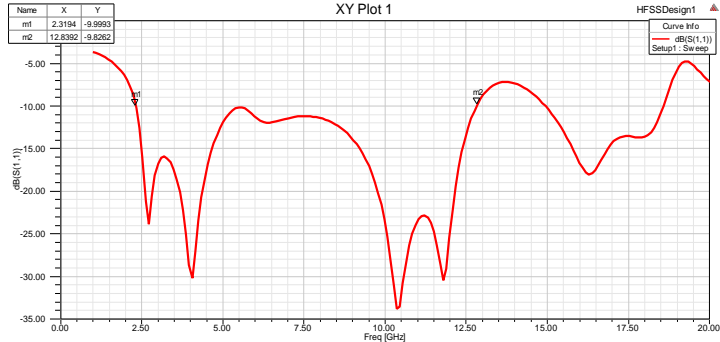

Figure 2(a): RL of UWB Antenna

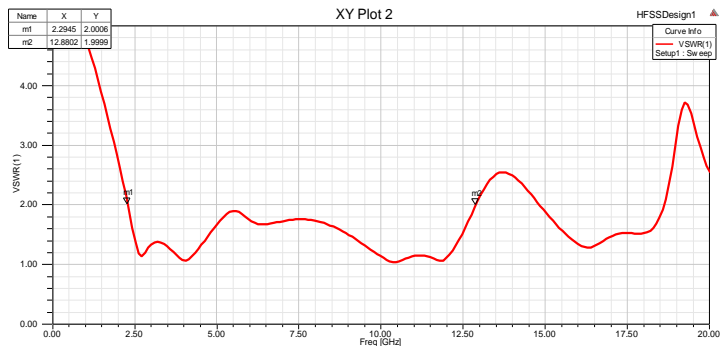

Figure 2(b): VSWR of UWB Antenna

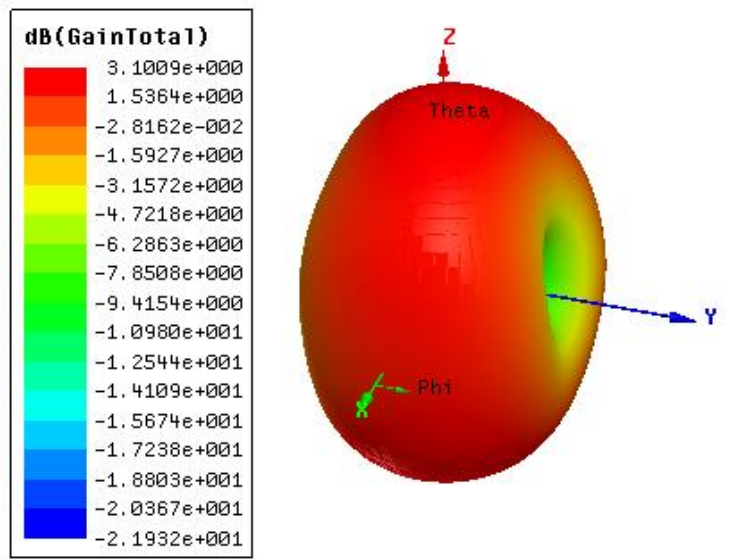

Figure 2(c): 3D Gain of UWB Antenna

The above figures 2 (a), (b), (c) represents that the basic UWB antenna has obtained acceptable performance in terms of Return loss, VSWR \& Gain.

\section{Design of Notches}

\subsection{Rejection of WLAN band}

For notching WLAN band the U-shaped slot is inserted as shown in figure 3 is made on rectangular part of patch. U- Shaped slot is formed by combining 3 slots as a single slot. The design specifications of U-slot are shown in table 2. 


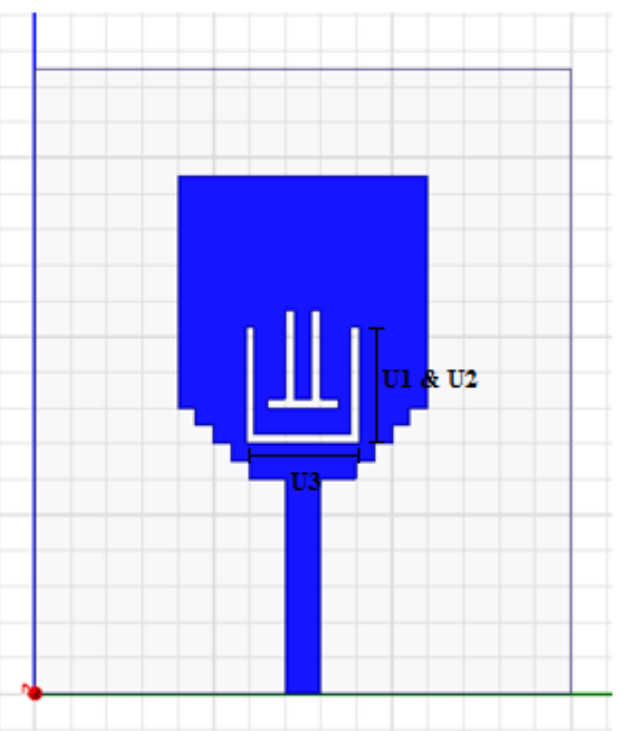

Figure 3: UWB antenna with WLAN notch (U-Shaped)

Table 2: U-slot dimensions for WLAN notch

\begin{tabular}{|c|c|c|}
\hline S.No. & Parameter & Value in mm \\
\hline 1 & U1(U-slot) & $(0.5,6)$ \\
\hline 2 & U2(U-slot) & $(0.5,6)$ \\
\hline 3 & U3 (U-slot) & $(6.4,0.5)$ \\
\hline
\end{tabular}

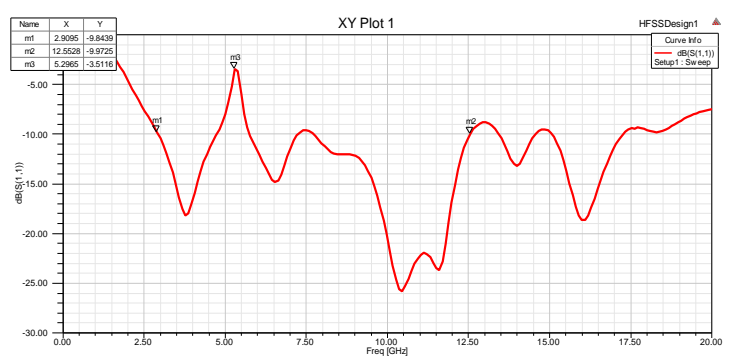

Figure 3(a): RL of UWB with WLAN notch

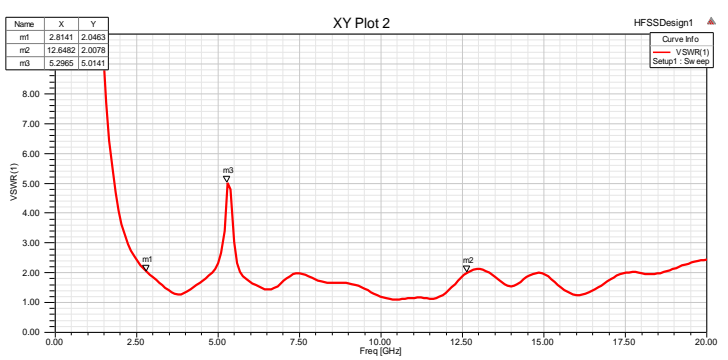

Figure 3(b): VSWR of UWB with WLAN notch
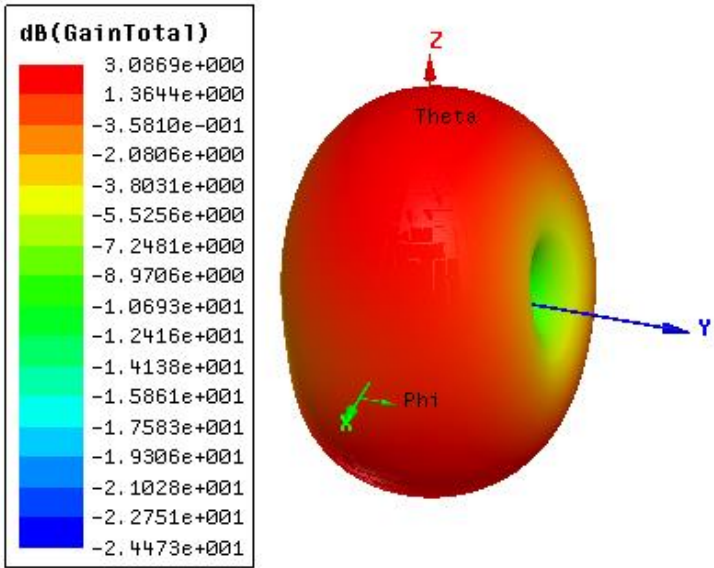

Figure 3(c): 3D Gain of UWB with WLAN notch

\subsection{Rejection of X-Band}

For notching X-band $7.25 \mathrm{GHz}$ to $7.75 \mathrm{GHz}$ (Space to Earth) an inverted $\mathrm{T}$ - slot is made on ground exactly at the center as shown in figure 4. Inverted T- shape is formed by uniting two rectangle slots whose dimensions will be specified in table 3 .

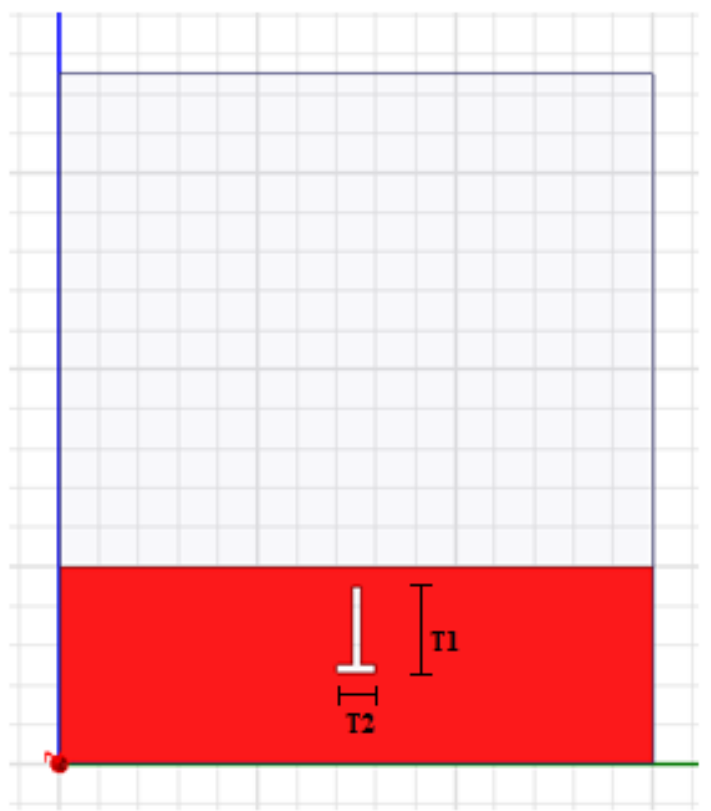

Figure 4: UWB antenna with X-Band notch in ground plane (inverted T-Shaped)

Table 3: Inverted T-slot dimensions for X-Band notch

\begin{tabular}{|c|c|c|}
\hline S.No. & Parameter & $\begin{array}{c}\text { Value } \\
\text { in } \mathbf{~ m m}\end{array}$ \\
\hline 1 & T1(inverted T-slot) & $(0.4,4)$ \\
\hline 2 & T2(inverted T-slot) & $(2,0.4)$ \\
\hline
\end{tabular}




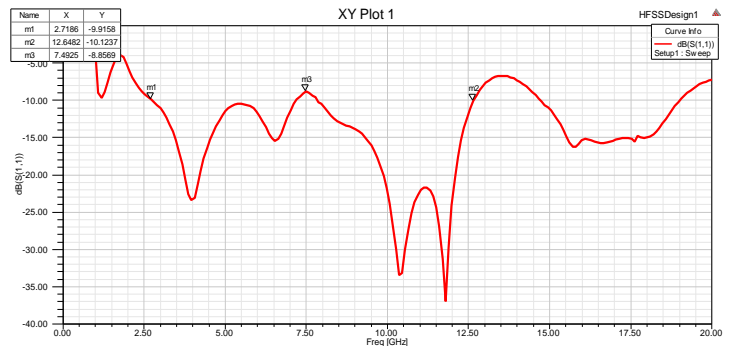

Figure 4(a): RL of UWB with X-Band notch

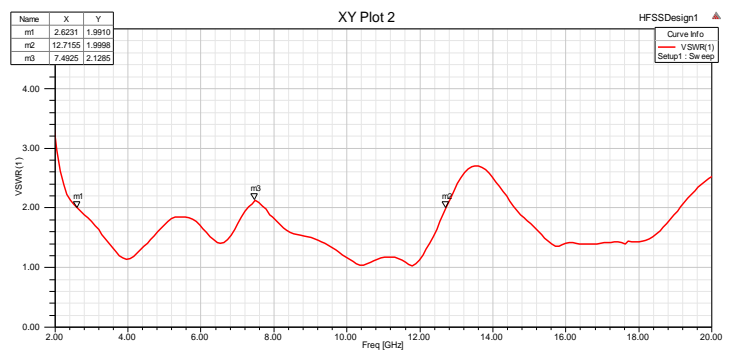

Figure 4(b): VSWR of UWB with X-Band notch

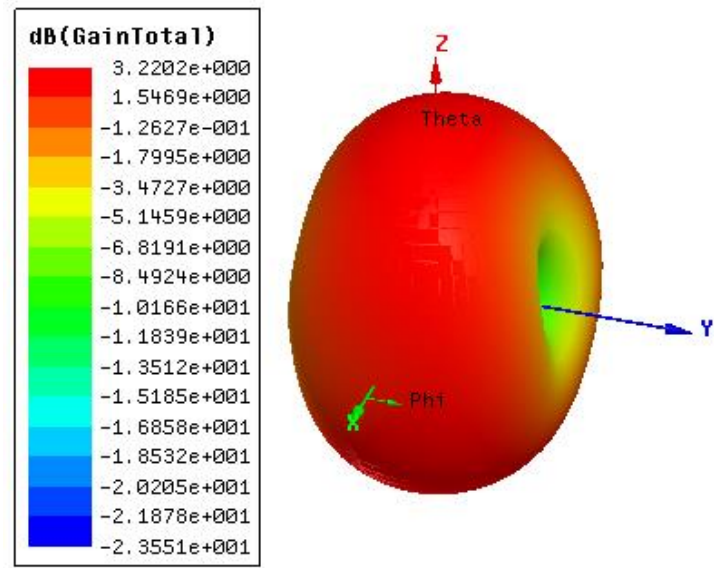

Figure 4(c): 3D Gain of UWB with X-Band notch

\subsection{Proposed UWB antenna with Dual notches}

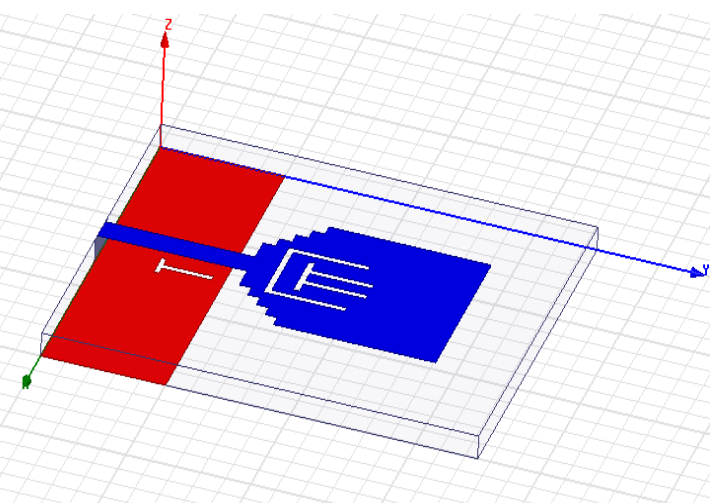

Figure 5: UWB with dual notch

The above figure 5 represents the UWB antenna with dual notches. On the upper side of the patch the U-shaped slot and the inverted T-slot at the ground plane are embedded. The projected antenna rejects two bands as seen in the response of the following graphs.

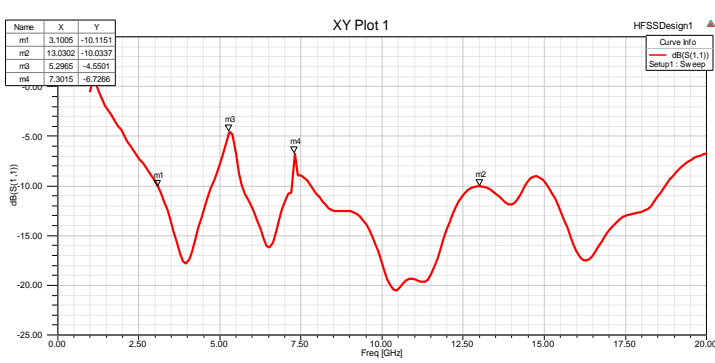

Figure 5(a): RL of UWB with dual notch

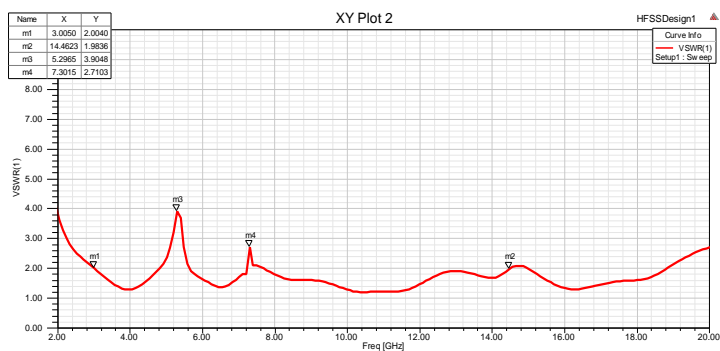

Figure 5(b): VSWR of UWB with dual notch

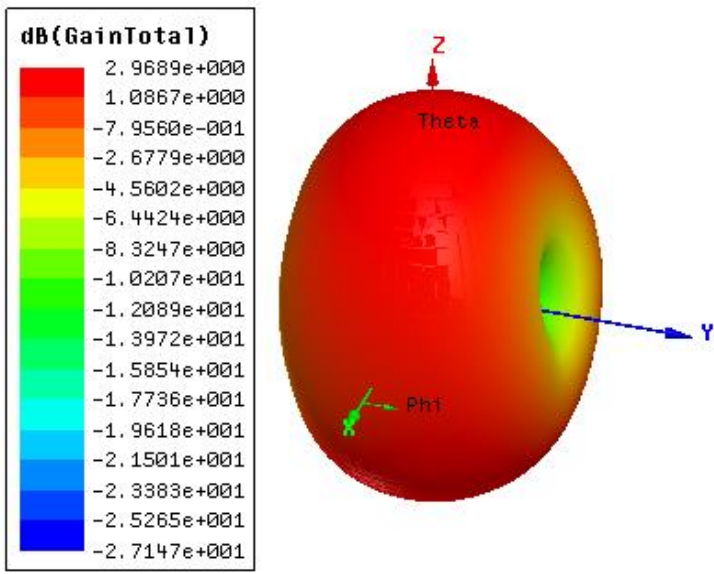

Figure 5(c): 3D Gain of UWB with dual notch

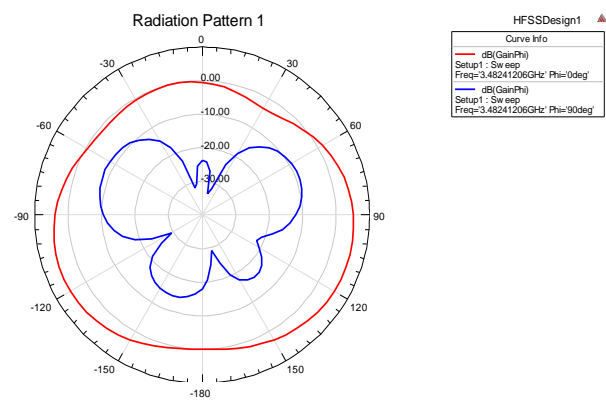

Figure 5(d): E-Plane radiation pattern at $3.48 \mathrm{GHz}$ 


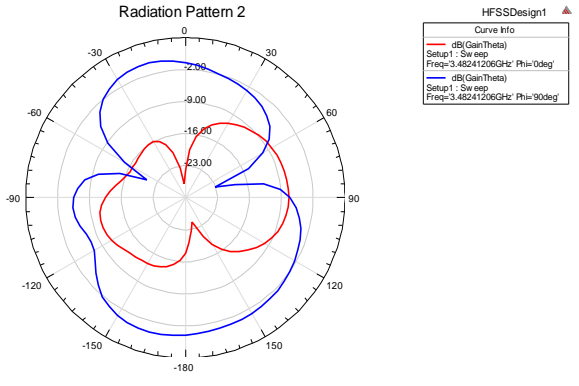

Figure 5(e): H-Plane radiation pattern at $3.48 \mathrm{GHz}$

\section{Conclusion}

Finally, the new staircase based UWB antenna with compact size has been designed by inserting inverted $\pi$-shaped slot to obtain the FCC allotted bandwidth. Also rejected WLAN \& X-band successfully by acceptable results in terms of return loss, VSWR \& Gain

\section{References}

[1]. Kenny Seungwoo Ryu,Ahmed A. Kishk "UWB Antenna With Single or Dual Band-Notches for Lower WLAN Band and Upper WLAN Band" IEEE Transactions on a antennas and propagation, volume 57,No.12 December 2009

[2]. Raviraj C. Jain1, Mahesh M. Kadam2 "BAND NOTCHING METHODS USED IN UWB ANTENNAS- A STUDY" CIRJET Volume: 02 Issue: 07 | Oct-2015 e-ISSN: 2395 -0056,p-ISSN: 2395-0072.

[3]. FCC Website [Online]. Available: www.fcc.gov/pshs/techtopics/techtopics10.html

[4]. J. Yeo and R. Mittra, "A novel wideband antenna package design with a compact spatial notch filter for wireless applications," Microw. Opt. Technol. Lett., vol. 35, pp. 455-460, 2002.

[5]. S. J. Hong, J. W. Shin, H. Park, and J. H. Choi, "Analysis of the band-stop techniques for ultra-wideband antenna," Microw. Opt. Technol. Lett., vol. 49, pp. 1058-1062, 2007.

[6]. S. Hu, H. Chen,C.L.Law,Z.Shen, L. Zui, W. Zhang, and W. Dou, "Back Scattering Cross Section of Ultra-Wide Band Antennas," IEEE Trans. Wireless Propagation Letter, vol. 6, pp. 70-73, 2007.

[7]. W. S. Lee, D. Z. Kim, K. J. Kim, and J. W. Yu, "Wideband planar monopole antennas with dual band-notched characteristics," IEEE Trans. Microw. Theory Tech., vol. 54, pp. 2800-2806, 2006.

[8]. W. C. Liu and S. M. Chen, "Ultra-wideband printed fork-shaped monopole antenna with a band-rejection characteristic," Microw. Opt. Technol. Lett., vol. 49, pp. 1536-1538, 2007.

[9]. Y. L. Zhao, Y. C. Jiao, G. Zhao, L. Zhang, Y. Song, and Z. B. Wong, "Compact planar monopole UWB antenna with bandnotched characteristic," Microw. Opt. Technol. Lett., vol. 50, pp. 2656-2658, 2008

[10]. Y. Kim and D.-H. Kwon, "CPW-fed planar ultra-wideband antenna having a frequency band notch functions," Electron. Lett., vol. 40, no.7, pp. 403-404, 2004.

[11]. Q.-X. Chu and Y.-Y. Yang, "A compact ultra-wideband antenna with 3.4/5.5 GHz dual band-notched characteristics," IEEE Trans. Antennas Propag., vol. 56, no. 12, pp. 3637-3644, Dec. 2008.

[12]. S.-W.Qu, J.-L. Li, and Q. Xue, "A band-notched ultra-wideband printed monopole antenna," IEEE Antennas Wireless Propag. Lett. vol. 5, pp. 495-498, 2006.

[13]. Raman, Y.S.V., Madhav, B.T.P., Mounika, G., Sai Teja, K., Sai Kumar, S.B.V.N. And Sri Harsha, K., 2016. Analysis Of Circularly Polarized Notch Band Antenna With Dgs. Arpn Journal Of Engineering And Applied Sciences, 11(17), Pp. 10140-10150.

[14]. Madhav, B.T.P., Chhatkuli, S., Manikantaprasanth, A., Bhargav, Y., Dinesh Naga Venkata Sai, U. And Feeraz, S., 2014. Measurement Of Dimensional Characteristics Of Microstrip Antenna Based On Mathematical Formulation. International Journal Of Applied Engineering Research, 9(9), Pp. 1063-1074.

[15]. Srinivas, M.S.S.S., Ramakrishna, T.V., Madhav, B.T.P., Bhagyalakshmi, N., Madhavi, S. And Venkateswarulu, K., 2015. A Novel Compact Cpw Fed Slot Antenna With Ebg Structure. Arpn Journal Of Engineering And Applied Sciences, 10(2), Pp. 835-841.
[16]. Ramkiran, D.S., Madhav, B.T.P., Prasanth, A.M., Harsha, N.S Vardhan, V., Avinash, K., Chaitanya, M.N. And Nagasai, U.S., 2015. Novel Compact Asymmetrical Fractal Aperture Notch Band Antenna. Leonardo Electronic Journal Of Practices And Technologies, 14(27), Pp. 1-12.

[17]. Ajay Babu, M., Madhav, B.T.P., Naga Vaishnavi, D., Radhakrishna, P., Bharath, N., Madhuri, K., Bhavani Prasad, K. And Harish, K., 2015. Flared V-Shape Slotted Monopole Multiband Antenna With Metamaterial Loading. International Journal On Communications Antenna And Propagation, 5(2), Pp. 93-97.

[18]. Lakshmi, M.L.S.N.S., Khan, H. And Madhav, B.T.P., 2015. Novel Sequential Rotated $2 \times 2$ Array Notched Circular Patch Antenna. Journal Of Engineering Science And Technology Review, 8(4), Pp. 73-77.

[19]. Madhav, B.T.P., Kaza, H., Vaka, J.K., Sravan Kumar, K., Sriharsha, N., Jaswanth Kumar, J., Siddharth, D.S. And Sai Teja Reddy, D., 2015. Design And Analysis Of Compact Coplanar Wave Guide Fed Asymmetric Monopole Antennas. Research Journal Of Applied Sciences, Engineering And Technology, 10(3), Pp. 247-252.

[20]. Sri Ramkiran, D., Madhav, B.T.P., Haritha, N., Ramya, R.S., Vindhya, K.M. And Abhishek, S.P., 2014. Design And Analysis Of Microstrip Slot Array Antenna Configuration For Bandwidth Enhancement. Leonardo Electronic Journal Of Practices And Technologies, 13(25), Pp. 72-83.

[21]. Madhav, B.T.P., Mohan Reddy, S., Ravindranath Chowdary, J., Vinod Babu, V., Satya Parthiva, S. And Kalyana Saravana, S., 2013. Analysis Of Dual Feed Asymmetric Antenna. International Journal Of Applied Engineering Research, 8(4), Pp. 461-467.

[22]. Madhav, B.T.P., Ujwala, D., Khan, H., Tejaswani, A.L., Guntupalli, S. And Bala, A., 2013. Substrate Permittivity Effects On The Performance Of Slotted Aperture Stacked Patch Antenna. International Journal Of Applied Engineering Research, 8(8), Pp. 909-916.

[23]. Sadasivarao, B. And Madhav, B.T.P., 2014. Analysis Of Hybrid Slot Antenna Based On Substrate Permittivity. Arpn Journal Of Engineering And Applied Sciences, 9(6), Pp. 885-890.

[24]. Lakshmikanth, P., Takeshore, K. And Madhav, B.T.P., 2015. Printed Log-Periodic Dipole Antenna With Notched Filter At 2.45 Ghz Frequency For Wireless Communication Applications. Journal Of Engineering And Applied Sciences, 10(3), Pp. 40-44.

[25]. Madhav, B.T.P., Sanikommu, M., Pranoop, M.S., Bose, K.S.N.M.C. And Kumar, B.S., 2015. Cpw Fed Antenna For Wideband Applications Based On Tapered Step Ground And Ebg Structure. Indian Journal Of Science And Technology, 8, Pp. 119-127.

[26]. Madhav, B.T.P., Kumar, K.V.V. And Manjusha, A.V., 2014. Analysis Of Cpw Fed Step Serrated Ultra Wide Band Antenna On Rogers Rt/Duroid Substrates. International Journal Of Applied Engineering Research, 9(1), Pp. 53-58.

[27]. Mohan Reddy, S.S., Mallikarjuna Rao, P. And Madhav, B.T.P., 2015. Asymmetric Defected Ground Structured Monopole Antenna For Wideband Communication Systems. International Journal On Communications Antenna And Propagation, 5(5), Pp. 256-262.

[28]. Madhav, B.T.P., Manikanta Prasanth, A., Prasanth, S., Krishna, B.M.S., Manikantha, D. And Nagasai, U.S., 2015. Analysis Of Defected Ground Structure Notched Monopole Antenna. Arpn Journal Of Engineering And Applied Sciences, 10(2), Pp. $747-$ 752 . 